\title{
Projection of future hot weather events and potential population exposure to this in South Korea
}

\author{
Changsub Shim ${ }^{1, *}$, Jihyun Seo ${ }^{1}$, Jihyun Han ${ }^{1}$, Jongsik Ha ${ }^{1}$, Tae Ho Ro ${ }^{1}$, \\ Yun Seop Hwang ${ }^{2}$, Jung Jin $\mathrm{Oh}^{3}$ \\ ${ }^{1}$ Korea Environment Institute, 30147 Sejong, ROK \\ ${ }^{2}$ Department of International Business and Trade, Kyung Hee University, 02453 Seoul, ROK \\ ${ }^{3}$ Department of Chemistry, Sookmyung Women's University, 04312 Seoul, ROK
}

\begin{abstract}
Heat waves, often caused by consecutive severe hot weather events, are responsible for the majority of medical costs associated with climate change in South Korea. In this study, we obtained a regional climate change scenario (RCP4.5) for South Korea, with $7.5 \times 7.5 \mathrm{~km}$ horizontal resolution and extending up to 2100 , by dynamically downscaling from results of the Community Earth System Model (CESM) with the Weather Research and Forecasting (WRF) model. We analyzed hot weather events (daily maximum temperature $>33^{\circ} \mathrm{C}$ ) in summer (June-August), focusing on changes in extent and frequency. According to our analysis, the area exposed to hot weather events in August will expand to cover $\sim 70 \%$ of the nation in the middle of this century, with a rate of increase of $0.24 \% \mathrm{yr}^{-1}$. We calculated the population exposed to hot weather events in Korea, considering both spatial coverage and number of event days. Population exposure was projected to increase almost 3 -fold, from $26 \%$ of the national population during the 2010 s to $72 \%$ during the 2090s. In particular, exposure of the elderly population (>65 yr old), who are particularly vulnerable, was expected to rapidly increase, with $\sim 22 \%$ of the national population $(\sim 10.4$ million people aged $>65 \mathrm{yr}$ ) affected in the middle of this century when we considered the future projection of rapid aging of the South Korean population structure. Our projection of extensive hot weather events starting from the middle of the 21st century suggests the need for urgent government long-term measures and enforcement to ensure an early response to extreme weather events in Korea.
\end{abstract}

KEY WORDS: Climate change $\cdot$ Climate vulnerability $\cdot$ Hot weather $\cdot$ Korea $\cdot$ Population exposure $\cdot$ Representative Concentration Pathways $\cdot$ RCP scenarios

\section{INTRODUCTION}

Heat waves, which are generally defined as extreme weather conditions due to an extended period of unusually high air temperature, often lead to adverse health consequences (Robinson 2001) and great economic loss (Meehl et al. 2000, Beniston \& Stephenson 2004, Kysely \& Huth 2004, Knowlton et al. 2011). In the USA, 10 major droughts/heat wave events in 1980-2003 accounted for the largest economic loss (US\$ 144 billion) among weather-related disasters (Ross \& Lott 2003). In South Korea, 3384

\footnotetext{
*Corresponding author: marchell@gmail.com
}

people died due to an unusual heat wave in 1994 (KMA 2012, 2013). There has been a warming trend since the 20th century in Korea, as indicated by the increase in daily summer maximum temperature (Choi et al. 2007, Na 2015). Specifically, maximum temperature has increased over the major cities of South Korea from 1961 to 2000, with a rate of increase of more than twice that of the global average $\left(0.028^{\circ} \mathrm{C} \mathrm{yr}^{-1}\right.$ for Seoul $)$, which includes the impact of urbanization (Choi et al. 2007).

The number of heat wave days in Korea in the 1990s and 2000s has ranged from 5 to 20 days $\mathrm{yr}^{-1}$

() The authors 2017. Open Access under Creative Commons by Attribution Licence. Use, distribution and reproduction are unrestricted. Authors and original publication must be credited. 
under different heat wave definitions, and the occurrence of heat waves in Korea has increased over this period (Park et al. 2008, Son et al. 2012). In particular, heat waves have been more intense over southern provinces (including the Yong-Nam and Ho-Nam regions) (B. C. Choi et al. 2007, G. Y. Choi et al. 2008, Jeung et al. 2013, KMA 2013, Kim et al. 2014, Na 2015), and heat wave warnings or alerts were issued for most regions of Korea in summer 2013 (KMA 2013).

Heat waves in South Korea are most intense in late July through early August and the mortality rate is highest for people aged >65 yr due to their impaired ability to adapt to heat (Woodward \& Scheraga 2003, Kim et al. 2006, Lee 2015). Not including the extreme heat wave disaster in 1994, the death toll due to heat waves has continued to rise since the 1990s (Park et al. 2008, Kim et al. 2014, Lee 2015).

Knowledge of potential extreme events in the future climate is necessary for the development of national plans for adaptation. According to the IPCC, global average surface temperature is projected to rise by $1.1-6.4^{\circ} \mathrm{C}$ by the 2090 s (compared to $1980-$ 1999; IPCC 2007). The frequency, intensity, and duration of heat waves will likely increase in the future (IPCC 2014). In addition, it has been reported that the adverse impacts on health of increased heat wave frequency in the future greatly outweigh the benefits of reduced cold spells associated with climate change (Kinney et al. 2012, Ebi \& Mills 2013), due in part to the larger and more immediate rises in mortality caused by heat waves (Deschênes \& Moretti 2009). For the USA, the Representative Concentration Pathway (RCP) scenarios suggest that mortality risks at the end of this century are expected to increase by an order of magnitude compared with the current risk (2002-2004) (Wu et al. 2014).

A number of studies have been conducted regarding future hot weather patterns and the responses required for the vulnerable population in Korea. According to RCP-based climate scenarios, future hot weather is likely to occur in the metropolitan area over the central regions (e.g. Seoul Metropolitan Area [SMA] with a population of $\sim 20$ million) and the southern regions of Korea (Jeung et al. 2013, Park et al. 2013). Park et al. (2013) concluded that most regions of South Korea, except for the mountainous regions, will have $>30 \mathrm{~d}$ of heat waves in 2070, based on RCP8.5. Mortality due to heat waves is also expected to increase accordingly, with the current rate of 0.7 deaths per 100000 population in 20012010 increasing to 1.5 deaths per 100000 population in 2040 (Yang \& Ha 2013).
The present study used the RCP4.5 scenario, which represents relatively moderate greenhouse gas mitigation to stabilize radiative forcing at $4.5 \mathrm{~W} \mathrm{~m}^{-2}$ in this century, to analyze the future projection of hot weather events in Korea. Our RCP4.5 scenario for Korea is based on the Community Earth System Model (CESM) developed by the US National Center for Atmospheric Research (NCAR), and the global model results were downscaled by a regional-scale meteorological model (Weather Research and Forecasting [WRF]) to obtain a climate scenario with a horizontal resolution of $7.5 \times 7.5 \mathrm{~km}$ over Korea.

With the estimated regional climate scenario for Korea, we investigated the projection of hot weather events regarding the spatial distribution and the cumulative number of days where a hot weather event is experienced in the 21st century. Additionally, this study investigated changes in the population exposed to hot weather events in Korea by estimating the population of affected administrative districts with corresponding model grids. Estimation of the exposed population can be used to gauge the potential health effects of hot weather events in the future, which is critical information for developing national adaptation measures to climate change in Korea.

The main objective of this study was to estimate the future population exposed to hot weather events in Korea based on the national-level climate scenario in order to support a long-term national policy.

\section{DATA AND METHODOLOGY}

\subsection{Dynamical downscaling of global climate model results}

We used the RCP4.5 scenario over Korea, which is based on results of the CESM model (www.cesm. ucar.edu/models) with a spatial resolution of $1.9^{\circ} \times$ $2.5^{\circ}$. CESM is a climate model that simulates the Earth's climate system and consists of submodels of the atmosphere (CAM), ocean (OCN), land (CLM), sea ice (CICE), and land ice (GLC). These submodels are connected through a coupler (CPL) that exchanges the feedbacks. We used CESM (v.1.0), developed by the NCAR and supported by the National Science Foundation (NSF) and Department of Energy (DOE), USA. WRF is a mesoscale numerical weather prediction model designed to support atmospheric forecasting and research by providing a variety of dynamic cores, with data assimilation and parallel computing (www.wrf-model.org/index.php/). 
To dynamically downscale the CESM results, meteorological variables from the CESM model were used as the initial and boundary conditions for the WRF (v.3.3) model at $6 \mathrm{~h}$ intervals to produce regional-scale scenarios with a $7.5 \times 7.5 \mathrm{~km}$ spatial resolution for the Korean Peninsula for 2006-2100. Detailed methodology for the dynamical downscaling has been reported previously by Seo et al. (2013). Fig. 1 shows the model domain for the CESM and the boundary of the WRF model for dynamic downscaling.

\subsection{Bias correction based on ground observations}

The climate model results inherently contain uncertainties, which can be amplified during the downscaling (Ho et al. 2011). It is agreed that downscaled surface variables, such as precipitation and temperature, should be comparable to observations to ascertain credibility in the projected scenarios (Lee et al. 2014).

Bias correction was estimated from the difference between simulated and observation data on a monthly basis from 2006 to 2014. The calculated bias correction was applied to the future climate projection, as in previous studies (delta change approach) (e.g. Graham et al. 2007, Sperna Weiland et al. 2010, Ho et al. 2012).

Observation data from 400 nationwide ground stations were used for bias correction over South
Korea. To undertake bias correction for temperature, we mapped the observational points with the corresponding model grid $(7.5 \times 7.5 \mathrm{~km})$ considering geographical elevation. If the model grid contained a measurement station, bias was calculated directly. If the model grid did not contain a measurement station, data from the closest adjacent station were used to calculate bias over the shortest distance, which is similar to the gap-filling process for missing satellite observations where the interpolation of surrounding good-quality data is used to cover gaps (Zhao et al. 2011). This grid-based bias correction was applied to monthly temperatures from 2006 to 2014 . The estimated bias for each grid was applied to the climate scenarios for the future projection of temperature.

Although there are many definitions of heat waves, we adopted the current official definition used by the Korea Meteorological Administration (KMA), i.e. a daily maximum temperature $>33^{\circ} \mathrm{C}$, based on regional information for health impacts (KMA 2013, Park et al. 2013). Because this definition simply classifies single days based on a predefined temperature threshold, we adopted the term 'hot weather events' for clarity. Hot weather events in Korea mostly occur in July and August, with the number of hot weather days being highest in August (Park et al. 2008, Kim et al. 2014). Based on the frequency of national hot weather events for the last $20 \mathrm{yr}$, we analyzed hot weather events in the Korean summer months (JuneAugust). $1.9^{\circ} \times 2.5^{\circ}$

$7.5 \mathrm{~km} \times 7.5 \mathrm{~km}$

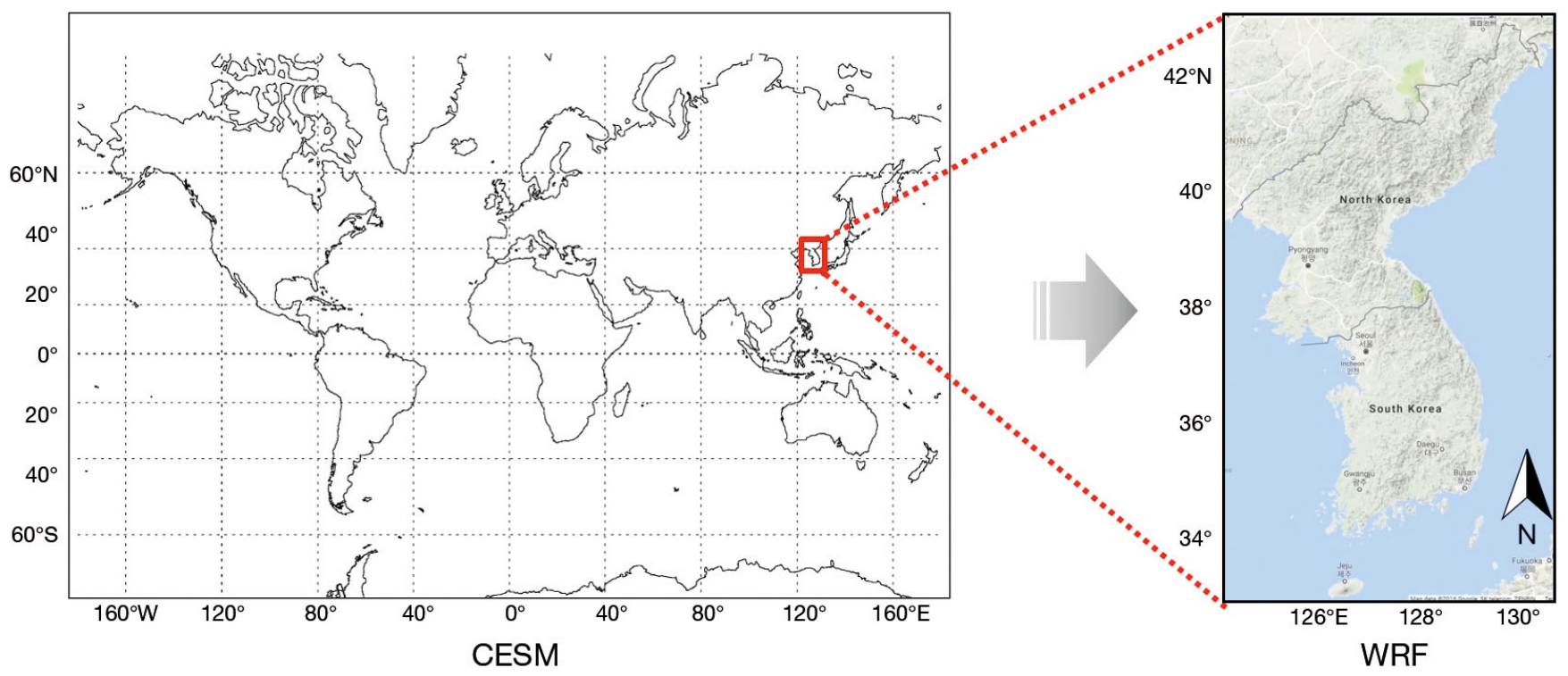

Fig. 1. Model domain for dynamic downscaling of climate scenarios from the global scale climate model Community Earth System Model (CESM; $1.9^{\circ} \times 2.5^{\circ}$ spatial resolution) (left) by the Weather Research and Forecasting model (WRF; $7.5 \times 7.5 \mathrm{~km}$ horizontal resolution) (right) 


\subsection{Considering both area and frequency of hot weather events}

We evaluate the national impact of hot weather events in terms of both area and frequency by integrating the area and frequency (IAF, \%) of hot weather events. IAF is defined here to evaluate the spatiotemporal extent of hot weather events. IAF is obtained by the integration of each unit of area with a hot weather event multiplied by the frequency (number of days), which is then divided by the area of the entire nation multiplied by the total number of days in the month, as follows:

$$
\operatorname{IAF}(\%)=\frac{\sum_{\mathrm{i}=1}^{h} A_{\mathrm{i}} d_{\mathrm{i}} \times 100}{\sum_{\mathrm{i}=1}^{t} A_{\mathrm{i}} D}
$$

where $A$ is the area of grid $i$ with a hot weather event, $h$ is the total number of grids with hot weather events, $d$ is the number of heat wave days in grid i, $t$ is the total number of grids over South Korea, and $D$ is the total number of days per month $(\sim 30 \mathrm{~d})$. For example, an IAF of $100 \%$ indicates that the entire area of South Korea is exposed to hot weather events every day during that month.

\subsection{Estimating population exposed to hot weather events}

One of the main objectives of this study was to estimate the future population that will be exposed to hot weather events in Korea. Estimation of the exposed population was undertaken by mapping the 228 administrative districts (vector data) containing population information to the geographical information on the corresponding model grid $(7.5 \times 7.5 \mathrm{~km}$, raster data). The area used for sampling was the model grid with total number of hot weather days per year $>11 \mathrm{~d}$, which was the average number of hot weather days over a 30 yr period (1981-2010; Na 2015). Population data, with age groups, for each administrative district, was based on 2010 data from the Korea Statistical Information Service (KOSIS) (http://kosis.kr/statHtml/statHtml.do?orgId=101\&tblId =DT_1IN0001_ENG\&conn_path=I3).

For mapping, we used ArcGIS (v.10.1) software, with the zonal statistics method. If one administrative district matched multiple grids, we selected the median value of temperature, which would show a more realistic current hot weather distribution than the mean value (not shown). Our estimation of total population exposure is based on data from 2010, which is not expected to change substantially until the middle of this century due to the low national birthrate and the limited residential area in Korea ( $65 \%$ of the nation is mountainous) (KOSIS 2015). However, changes in population structure are considered by 2060 , reflecting a rapidly aging society (KOSIS 2015).

\section{RESULTS}

\subsection{Distribution and frequency of hot weather events}

Fig. 2 displays the spatial distribution of the projection of daily maximum temperature $\left(T_{\max }\right)$ in summer with the RCP4.5 climate scenario on a monthly mean basis. Differences of future projection of $T_{\max }$ compared to the 2010s are presented in Fig. 3. While $T_{\max }$ was not expected to increase greatly over northwestern Korea in June until the 2050s, $T_{\max }$ over southeastern Korea increased markedly in the 2050s (Figs. $2 \& 3$ ). $T_{\max }$ was projected to increase over most regions of South Korea in the last decade of the 21st century, which was a similar pattern to the summer months over Korea (Figs. $2 \& 3$ ). An increase in $T_{\max }$ over the western coast and southeastern Korea in July in the 2050s and 2090s was noticeable (Figs. 2 \& $3)$, which was also reported previously by Choi et al. (2008), based on observations made over several decades. In particular, a generally higher $T_{\max }$ in August $\left(>35^{\circ} \mathrm{C}\right.$ ) was expected in the 2090s (Fig. 2), which is fairly remarkable considering that the projection was made with the RCP4.5 scenario that represents relatively moderate climate change.

Projection of the distribution of hot weather frequency (total number of hot weather days) over South Korea is shown in Fig. 4, and differences in the projected frequency compared to the 2010s are in Fig. 5. Similar to $T_{\max }$ the area affected by hot weather events was expected to expand over southeastern Korea (Young-Nam region) in the 2090s (Fig. 4). In addition to expansion of the area affected by hot weather events in July and August, the higher number of hot weather days $\left(>15 \mathrm{~d} \mathrm{mo}^{-1}\right.$ ) over the western and southeastern regions of Korea are expected in the last decade of the 21st century (in July and August; Figs. 4 \& 5). Similar projections were also made by Jeung et al. (2013) and Park et al. (2013), although with different extreme weather definitions and using different climate scenarios.

To investigate hot weather event projection, we focused on 2 factors: expansion of the area affected by hot weather events, and frequency (number of days). 


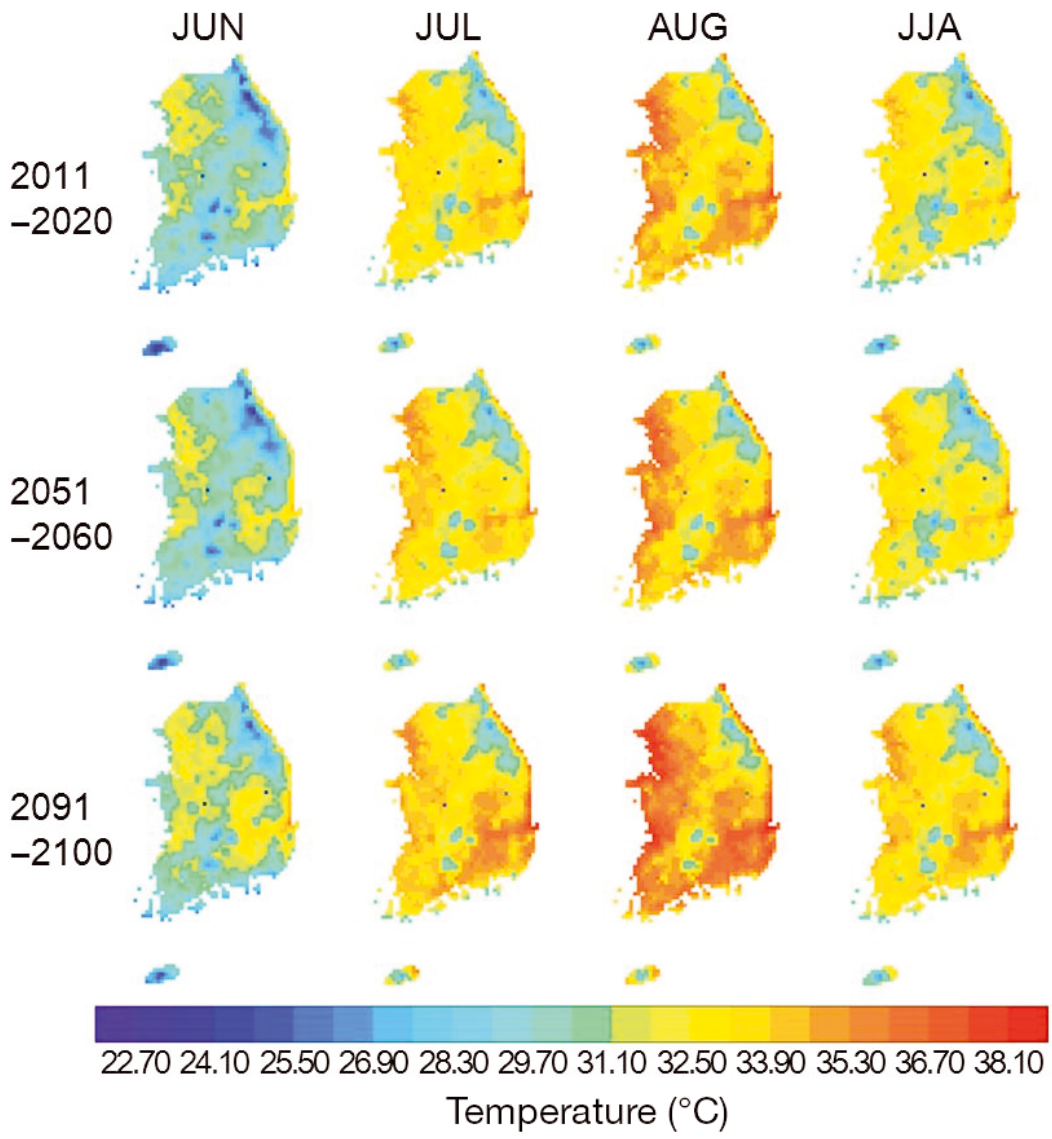

Fig. 2. Distribution of daily maximum temperature $\left(T_{\max }\right)$ of South Korea in June, July, August, and the summer mean (average of JJA), for 3 decadal bins (2011-2020, 2051-2060, and 2091-2100)
We estimated expansion of the area affected by hot weather events by defining it as the area exposed to hot weather events more than once in a month. Fig. 6 shows the decadal trend of expansion of the area affected by hot weather events for each summer month, with the area affected by hot weather events expressed as a fraction (\%) of the total area of the country.

Although the area currently affected by hot weather events was not extensive in June $(<10 \%)$, it was projected to increase to almost $25 \%$ before 2040 , which is similar to the current area affected by hot weather events in July $(\sim 30 \%)$ (Fig. 6). The fastest expansion of the area affected by hot weather events occurred in July (Fig. 6). The current extent of the area affected by hot weather events (30\%) almost doubled by the end of this century, and the rate of increase was $0.29 \% \mathrm{yr}^{-1}$ (Fig. 6). In particular, a large expansion in the area affected by hot weather events in the 2060s was noticeable (Fig. 6). The area affected by hot weather events was largest in August and expanded at an average rate of $0.24 \% \mathrm{yr}^{-1}$, resulting in $70 \%$ of

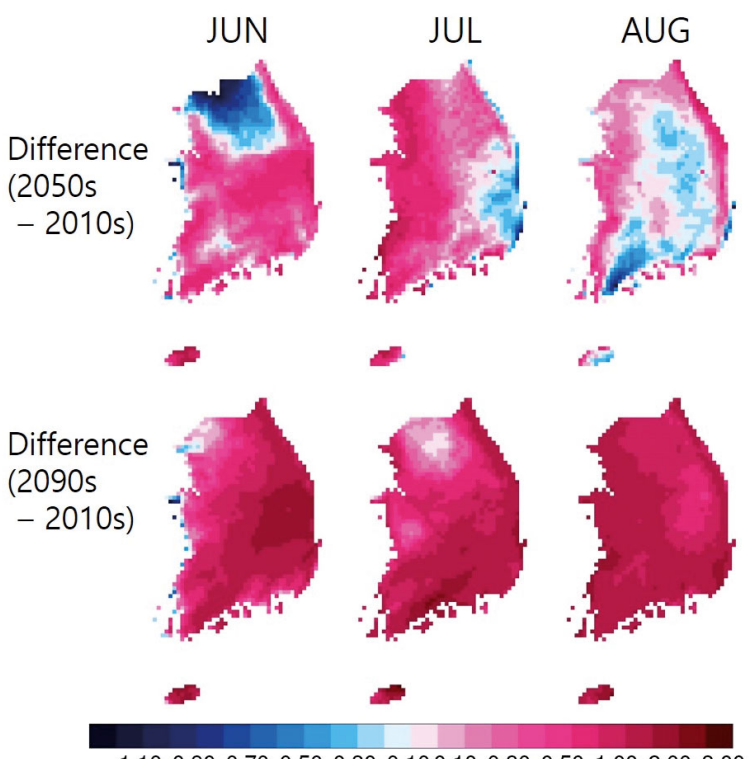

$-1.10-0.90-0.70-0.50-0.30-0.100 .100 .300 .501 .002 .003 .00$ $\Delta \mathrm{T}\left({ }^{\circ} \mathrm{C}\right)$

Fig. 3. Distribution of daily maximum temperature $\left(T_{\max }\right)$ of South Korea in June, July, and August, showing the differences between the 2050s and 2010s and the 2090s and 2010s
South Korea being exposed to hot weather events in the 2060s (Fig. 6).

Expansion of hot weather events in the 21st century is not linear with time, with instant drops predicted in the 2050s and 2080s (Figs. 6 \& 7). This is likely due to the complex geophysical response to external forcing and internal climate variability in the simulation (Manabe et al. 1990, Hall 2004, Seneviratne et al. 2010, Deser et al. 2012, Ishizaki et al. 2012, Good et al. 2015).

In addition to the area affected by hot weather events, we also considered the frequency of hot weather events by integrating the area and frequency of hot weather events (IAF, \%) (defined in Section 2.3). The nationwide IAF is currently $<5 \%$ in July, but was projected to increase to $10 \%$ in the 2060s (Fig. 7). IAF in August is a more serious concern. It was projected to increase sharply and reach $\sim 20 \%$ in the 2040s (Fig. 7). In the 2040s, IAF will reach $25 \%$, with an average rate of increase of $0.15 \% \mathrm{yr}^{-1}$ (Fig. 7). Our analysis indicated that the national frequency of hot weather events and the population's exposure to them will be severe in August, with a large potential mor- 


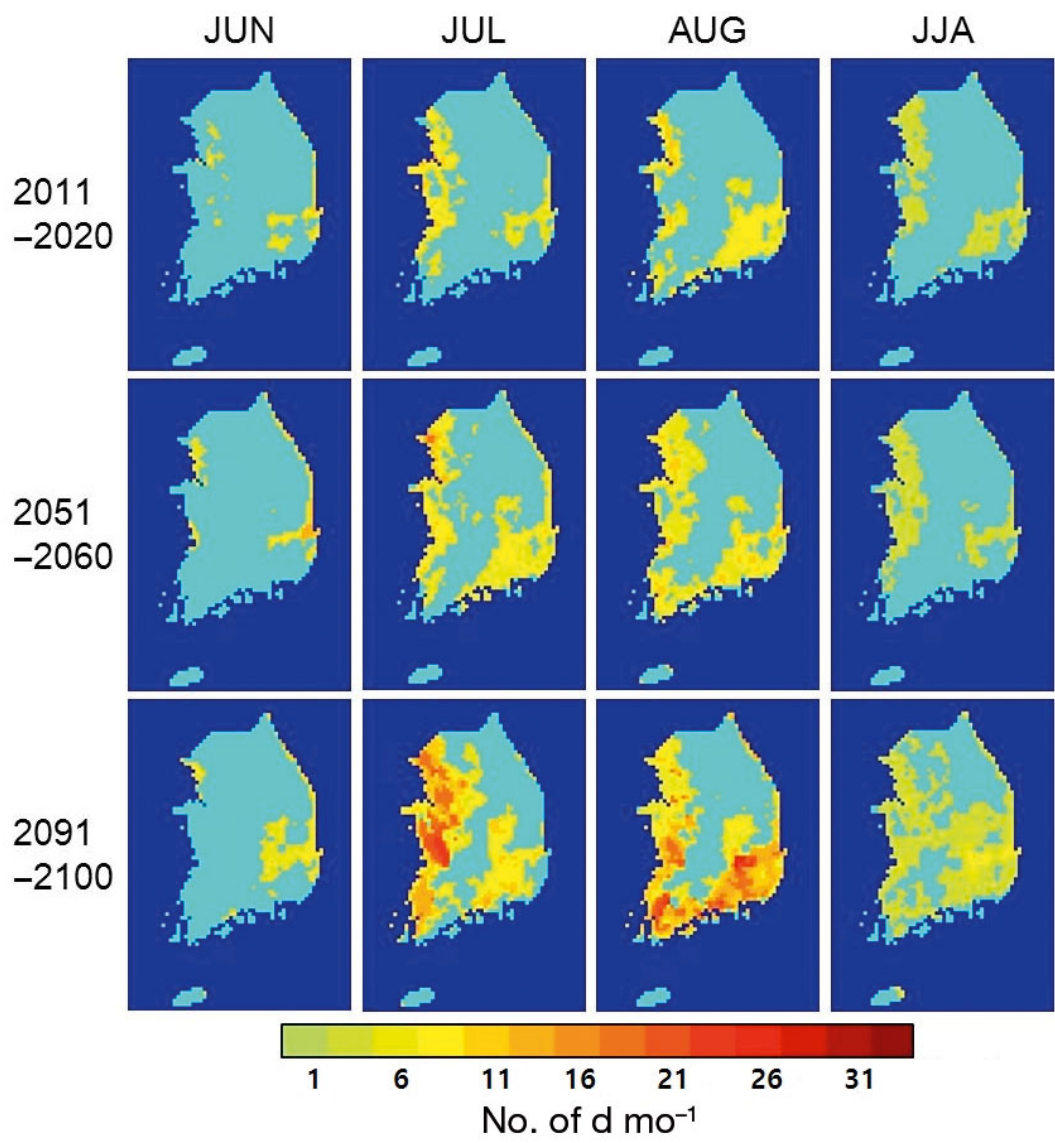

Fig. 4. Projection of hot weather frequency in South Korea in June, July, August, and the summer mean (JJA), for 3 decadal bins (2011-2020, 2051-2060, and 2091-2100)

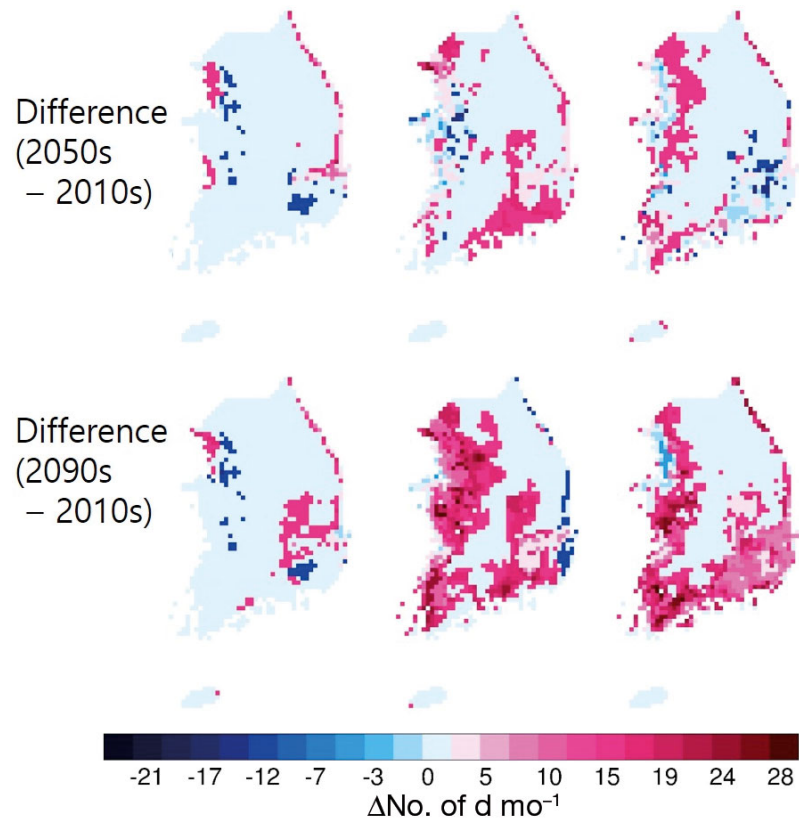

Fig. 5. Projection of hot weather frequency (number of days per month) in South Korea in June, July, and August, for the difference from the 2050s to 2010s and the 2090s to 2010s tality associated with the increased hot weather intensity in Korea.

\subsection{Population exposed to hot weather events}

As explained in Section 2.4, we estimated the population exposed to hot weather events in the summer months based on the mapping of local administrative districts and the model grid. Currently (2010), a quarter of the Korean population ( 12.5 million people) is exposed to hot weather events (Fig. 8). However, the exposed population was projected to rapidly increase to more than half of the total population $(58 \%$, 27.9 million) in the middle of this century (2050; Fig. 8), which is closely associated with the expansion of the area affected by hot weather events into the SMA and southeastern region, where there is higher population density (Figs. 4 \& 5). In the last decade of this century, the population exposed to hot weather events was projected to reach $72 \%$ of the total population, indicating that the majority of the nation's population will be exposed to hot weather events by the end of this century. Furthermore, the population structure in Korea is expected to change significantly. The Korean population is continuously aging and has been considered an 'aging society' since 2000 (Gong \& Jang 2010). The elderly population is projected to increase rapidly in the future (KOSIS 2015), and this portion of the population is particularly vulnerable to heat waves (McGeehin \& Mirabelli 2001, Schifano et al. 2009, Huang et al. 2010, Son et al. 2012), having significantly higher mortality from heat waves in South Korea, especially those > 65 yr of age (Lee 2015). Thus, we estimated the population exposure for the elderly ( $>65 \mathrm{yr}$ old) to hot weather events. Currently (2010), the population of $>65 \mathrm{yr}$ olds is about 5.5 million, accounting for $\sim 11 \%$ of the total population of South Korea.

If we apply the future changes in national population structure with the same spatial distribution of the population in 2010, our estimation shows that the $\sim 1.4$ million elderly exposed to hot weather events ( $\sim 3 \%$ of the national population) in 2010 could rapidly increase to $\sim 10.4$ million ( $22 \%$ of the national population) in 2050 (Fig. 8). 


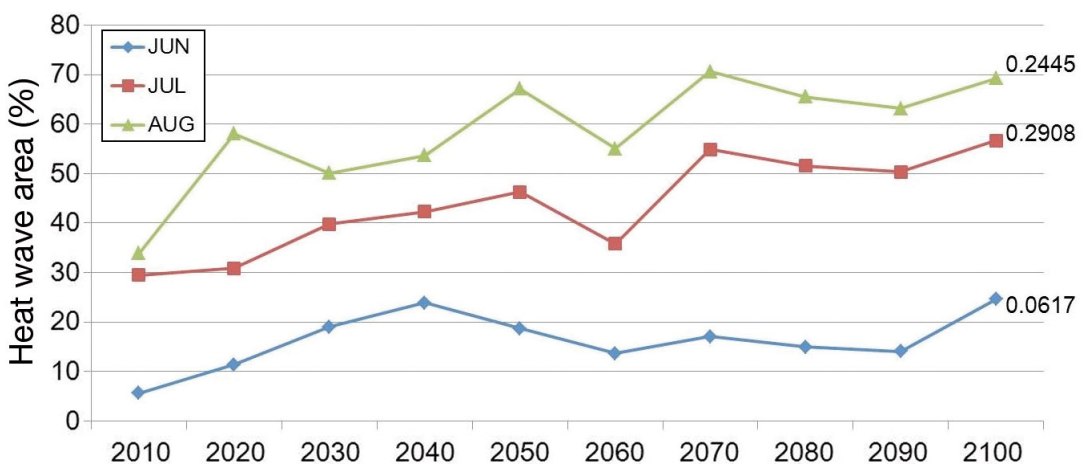

Fig. 6. Projection of area affected by hot weather events (\%) in South Korea, defined as the sum of the area experiencing $\geq 1$ hot weather event in each summer month (June-August), divided by the area of the entire nation. Numbers on the right side are the rate of increase ( $\%$ area per year) for each month

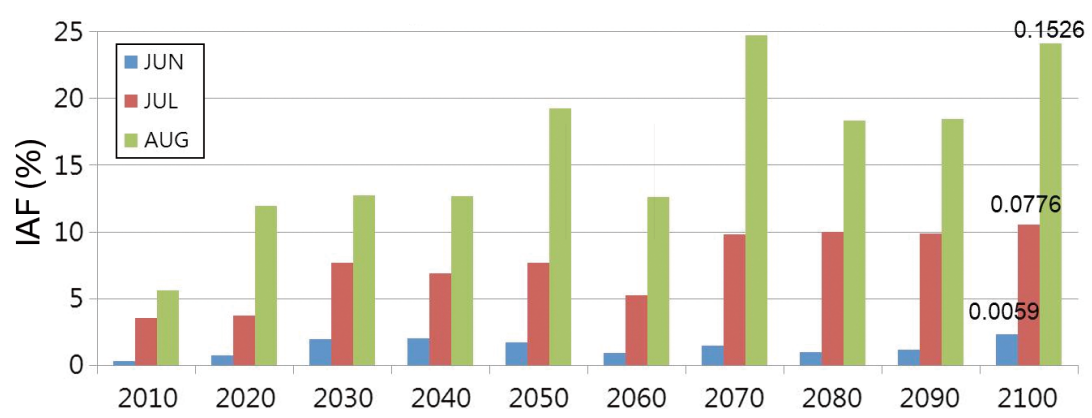

Fig. 7. Projection of integration of area and frequency (IAF) of hot weather events in South Korea (see Section 2.3 and Eq. 1 for definition). Numbers above bars for 2100 are the rate of increase of IAF (\% per year) for each month

\section{DISCUSSION AND CONCLUSIONS}

Here, we discuss the projections of hot weather events and the potential population exposure over South Korea in the 21st century. The regional RCP4.5 scenario, with a $7.5 \times$ $7.5 \mathrm{~km}$ horizontal resolution, was calculated by dynamical downscaling of CESM model results, in which the estimated temperature was validated by ground observations, and the mean bias was applied for future temperature projection.

This study first presented quantitative information on future projections of hot weather events in Korea with information on changes in the area affected and frequency for the entire nation. This study also estimated future nationwide population exposure to hot weather events, which is essential information for preparing national climate change adaptation policy.

Our analysis showed that the area affected by hot weather events will increase to cover $\sim 70 \%$ of the nation in August in the middle of this cen-

Exposed population

- Over 65 yr olds exposed

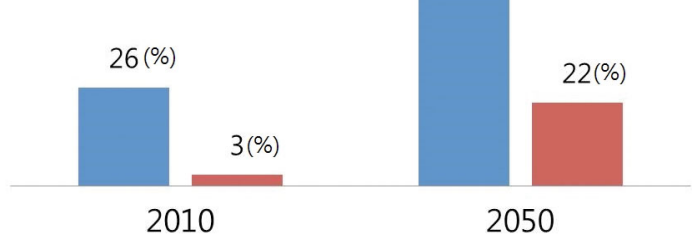

Fig. 8. Projection of population (overall and elderly) exposed to summer hot weather events in South Korea. A projection of the national population structure was used. Note that the population of $>65$ yr olds is considered to have significantly higher heat wave mortality in Korea

Although our estimation contains uncertainty from the assumption of a static population distribution due to lack of future data available at the local administrative district level, the uncertainty would be small, because the changes in the population structure at the regional administrative district level are small (KOSIS 2015). Our results therefore have important implications for future national security associated with climate change. tury, with an overall rate of increase of $0.24 \% \mathrm{yr}^{-1}$. In terms of frequency, the larger number of hot weather days $\left(>15 \mathrm{~d} \mathrm{mo}^{-1}\right)$ in the western and southeastern regions of Korea in the last decade of the 21st century is critical because the majority of the Korean population, nearly 30 million people, reside in these regions, which includes the SMA and Busan.

We introduced the index of integration of area and frequency (IAF, \%), which is a summation of the area affected by hot weather events multiplied by the number of heat wave days for each area. According to the IAF results, a quarter of the nation will be exposed to daily hot weather events in August during the 2060s and 2090s, which is almost a $500 \%$ increase compared with the 2000 s. An IAF of $25 \%$ can cause a great impact on the nation since it is statistically equivalent to a quarter of the nation being exposed to hot weather events every day of a month, or all of the nation being exposed to hot weather events for about $7.5 \mathrm{~d} \mathrm{mo}^{-1}$. IAF contains frequency information associated with hot weather intensity and duration, which is closely related to mortality (Son et al. 2012). Ho et al. (2011) also estimated the projection of heat waves. 
Although they used a different definition and the Special Report on Emissions Scenarios (SRES), they concluded that heat wave frequency will increase by $583 \%$ in the A1FI scenario, implying that our analysis with RCP4.5 was almost as serious as the previous analysis using the A1FI scenario.

In addition, we estimated the population exposed to hot weather events by mapping population data from the nation's administrative districts with the model grid. Despite the limitations and uncertainty in the projection of future population, the exposed population was projected to increase almost 3 -fold, from $26 \%$ during the 2010 s to $72 \%$ during the 2090 s. In particular, the exposure of the elderly population (>65 yr old), who are particularly vulnerable to heat waves, was expected to reach $\sim 22 \%$ of the national population ( 10.4 million) in the middle of this century if we apply the projection of an aging population to our results. It is important to note that those results are only based on the RCP4.5 scenario, implying that even more severe hot weather events could be expected under a possible business-as-usual scenario (e.g. RCP8.5).

The Korean government has taken actions against heat waves with an annual national plan for heat waves coordinated by the Ministry of Public Safety and Security (MPSS) and a national adaptation plan to climate change coordinated by the Ministry of Environment (MOE). However, cross-sectoral collaboration and engagement for regional-specific plans need to be improved (Ha et al. 2014). In particular, our results strongly suggest the need for long-term measures to mitigate the effects of heat waves, for which there are no current provisions (Ha et al. 2014).

This study may contain uncertainties for the following reasons. (1) Bias correction over a relatively short period $(9 \mathrm{yr})$ can ignore long-term interannual climate variability. We further estimated that the difference in monthly bias between the 9 yr period 20062014 and $30 \mathrm{yr}$ period 1985-2014 ranges from -0.04 to $0.45^{\circ} \mathrm{C}$ (national mean). Applying the bias correction over a $30 \mathrm{yr}$ period could reduce the number of total grids with hot weather events in summer by $16 \%$ (2015-2100), leading to reductions in population exposure of $50 \%$ (total population) and 19\% (elderly population) in 2050 (corresponding to Fig. 8). Although the application of the same approaches to bias correction with a $30 \mathrm{yr}$ period was not possible due to the much smaller number of ground stations $(\sim 70)$, these facts imply the possibility of the overestimated projections.

(2) There are uncertainties associated with the climate model schemes and downscaling method, which requires further study, including comparisons with multi-model scenarios, including those from the KMA (Jeung et al. 2013, Park et al. 2013), because the projection of heat wave mortality could be highly variable, depending on the exact climate model used (Ho et al. 2011, Peng et al. 2011).

(3) Heat waves earlier in the year can produce higher mortality than later heat waves (Son et al. 2012), and the Korean government has already issued heat wave alerts several times in May 2016 (Kim 2016), while the occurrence of heat waves in Korea used to be rare ( $<10$ in the last $20 \mathrm{yr}$; Kim et al. 2014). Thus, studies of early heat waves and their impacts on health are necessary.

Acknowledgements. This work was jointly supported by the Korea Meteorological Administration Research and Development Program under Grant KMIPA (No. 2015-2022) and the National Research Foundation of Korea (Nos. NRF-2013 S1A5B6043772 and NRF-2013R1A2A1A03070600) funded by the Ministry of Science, ICT and Future Planning (MSIFP). The system for producing regional climate scenarios was supported partly by the Korea Environmental Institute (KEI) and partly by the Korean Ministry of Environment (KMOE)'s Climate Change Correspondence Program. We thank Dr. Sung-Dae Kang and Ms. Jiyoun Hong for supporting our analysis of the CESM climate model. The CESM project is supported by the National Science Foundation and the Office of Science (BER) of the US Department of Energy.

\section{LITERATURE CITED}

Beniston M, Stephenson DB (2004) Extreme climate events and their evolution under changing climate conditions. Glob Planet Change 44:1-9

Choi BC, Kim JY, Lee DG, Kysely J (2007) Long-term trends of daily maximum and minimum temperatures for the major cities of South Korea and their implications on human health. Atmosphere (Korean Meteorol Soc) 17: 171-183

Choi GY, Kwon WT, Boo KO, Cha YM (2008) Recent spatial and temporal changes in means and extreme events of temperature and precipitation across the Republic of Korea. J Korean Geogr Soc 43:681-700

*Deschênes O, Moretti E (2009) Extreme weather events, mortality, and migration. Rev Econ Stat 90:659-681

Deser C, Knutti R, Solomon S, Phillips AS (2012) Communication of the role of natural variability in future North American climate. Nat Clim Change 2:775-779

*Ebi KL, Mills D (2013) Winter mortality in a warming climate: a reassessment. WIREs Clim Change 4:203-212

Gong S, Jang HJ (2010) A literature survey on environmental issues and life pattern changes of an aging society. Working Paper of Korea Environment Institute, Seoul (in Korean)

Good O, Lowe JA, Andrews T, Wiltshire A and others (2015) Nonlinear regional warming with increasing $\mathrm{CO}_{2}$ concentrations. Nat Clim Change 5:138-142

* Graham LP, Andréasson J, Carlsson B (2007) Assessing climate change impacts on hydrology from an ensemble of 
regional climate models, model scales and linking methods - a case study on the Lule River basin. Clim Change 81(Suppl 1):293-307

Ha J, Jung HC, Lee JH, Kim DH, Choi J (2014) A study on establishment and management of a long-term heatwave plan addressing climate change. Research Report of Korea Environment Institute, Sejong (in Korean)

Hall A (2004) The role of surface albedo feedback in climate. J Clim 17:1550-1568

Ho CH, Park TW, Jun SY, Lee MH and others (2011) A projection of extreme climate events in the 21st century over East Asia using the Community Climate System Model 3. Asia-Pac J Atmos Sci 47:329-344

*Ho CK, Stephenson DB, Collins M, Ferro CAT, Brown SJ (2012) Calibration strategies: a source of additional uncertainty in climate change projections. Bull Am Meteorol Soc 93:21-26

Huang W, Kan H, Kovats S (2010) The impact of the 2003 heat wave on mortality in Shanghai, China. Sci Total Environ 408:2418-2420

IPCC (2007) Climate change 2007: synthesis report. Summary for policymakers. Cambridge University Press, Cambridge

IPCC (2014) Climate change 2014: impacts, adaptation, and vulnerability. Contribution of Working Group II to the Fifth Assessment Report of the Intergovernmental Panel on Climate Change. Cambridge University Press, Cambridge

Ishizaki Y, Shiogama H, Emori S, Yokohata T and others (2012) Temperature scaling pattern dependence on representative concentration pathway emission scenarios. Clim Change 112:535-546

Jeung SJ, Sung JH, Kim BS (2013) Change projection of extreme indices using RCP climate change scenario. J Korea Water Resour Assoc 46:1089-1101

Kim Y (2016) The Korean government takes action against heat waves in 2016. Environmental News of Korea. www.hkbs.co.kr/?m=bbs\&bid=envnews7\&uid=394186 (accessed on May 23) (in Korean)

Kim H, Ha J, Park J (2006) High temperature, heat index, and mortality in 6 major cities in South Korea. Arch Environ Occup Health 61:265-270

Kim EB, Park JK, Jung WS (2014) A study on the occurrence characteristics of tropical night day and extreme heat day in the metropolitan city, Korea. J Environ Sci Int 23: 873-885

Kinney PL, Pascal M, Vautard R, Laaid K (2012) Winter mortality in a changing climate: Will it go down? Bull Epidemiol Hebd (Paris) 12-13:148-151

KMA (Korea Meteorological Administration) (2012) The annual report of extreme climate in 2012. KMA, Seoul (in Korean)

KMA (Korea Meteorological Administration) (2013) The annual report of extreme climate in 2013. KMA, Seoul (in Korean)

Knowlton K, Rotkin-Ellman M, Geballe L, Max W, Solomon GM (2011) Six climate change-related events in the United States accounted for about $\$ 14$ billion in lost lives and health costs. Health Aff 30:2167-2176

KOSIS (Korea Statistical Information Service) (2015). The projection of population structure. http://kosis.kr/statisticsList/ statisticsList_01List.jsp?vwcd=MT_ZTITLE\&parentId=A. (In Korean) (accessed October 19, 2015)

Kysely J, Huth R (2004) Heat-related mortality in the Czech Republic examined through synoptic and 'traditional' approaches. Clim Res 25:265-274
Lee J (2015) The damages of heat waves and responding strategy. Forum for responding to heat waves, Seoul, July 30, 2015. Korea Meteorological Administration, Seoul, p 67-69 (in Korean)

* Lee JW, Hong SY, Chang EC, Suh MS, Kang HS (2014) Assessment of future climate change over East Asia due to the RCP scenarios downscaled by GRIMs-RMP. Clim Dyn 42:733-747

Manabe S, Bryan K, Spelman MJ (1990) Transient response of a global ocean-atmosphere model to a doubling of atmospheric carbon dioxide. J Phys Oceanogr 20:722-749

* McGeehin MA, Mirabelli M (2001) The potential impacts of climate variability and change on temperature-related morbidity and mortality in the United States. Environ Health Perspect 109(Suppl 2):185-189

* Meehl GA, Karl T, Easterling DR, Changnon S and others (2000) An introduction to trends in extreme weather and climate events: observations, socioeconomic impacts, terrestrial ecological impacts, and model projections. Bull Am Meteorol Soc 81:413-416

Na D (2015) The meteorological characteristics of Korean summer in 2015 and the warning of heat waves. Forum for responding to heat waves, Seoul, July 30, 2015. Korea Meteorological Administration, Seoul, p 25-38 (in Korean)

Park JK, Jung WS, Kim EB (2008) A study on development of the extreme heat standard in Korea. J Environ Sci (China) 17:657-669

Park CY, Choi YE, Kwon YA, Kwon JI, Lee HS (2013) Studies on changes and future projections of subtropical climate zones and extreme temperature events over South Korea using high resolution climate change scenario based on PRIDE model. J Korean Assoc Reg Geogr 19: $600-614$

*Peng RD, Bobb JF, Tebaldi C, McDaniel L, Bell ML, Dominici F (2011) Toward a quantitative estimate of future heat wave mortality under global climate change. Environ Health Perspect 119:701-705

Robinson PJ (2001) On the definition of a heat wave. J Appl Meteorol 40:762-775

Ross T, Lott N (2003) A climatology of 1980-2003 extreme weather and climate events. Technical Report (2003-01) of National Climate Data Center, Asheville, NC

Schifano P, Cappai G, De Sario M, Michelozzi P and others (2009) Susceptibility to heat wave-related mortality: a follow-up study of a cohort of elderly in Rome. Environ Health 8:50

* Seneviratne SI, Corti T, Davin EL, Hirschi M and others (2010) Investigating soil moisture-climate interactions in a changing climate: a review. Earth-Sci Rev 99:125-161

* Seo J, Shim C, Hong J, Kang S, Moon N, Hwang YS (2013) Application of the WRF model for dynamical downscaling of climate projections from the Community Earth System Model (CESM). Atmosphere (Korean Meteorol Soc) 23:347-356

Son J, Lee JT, Anderson GB, Bell ML (2012) The impact of heat waves on mortality in seven major cities in Korea. Environ Health Perspect 120:566-571

Sperna Weiland FC, van Beek LPH, Kwadijk JCJ, Bierkens MFP (2010) The ability of a GCM-forced hydrological model to reproduce global discharge variability. Hydrol Earth Syst Sci 14:1595-1621

Woodward A, Scheraga JD (2003) Looking to the future: challenges for scientists studying climate change and health. In: McMichael AJ, Campbell-Lendrum DH, Cor-

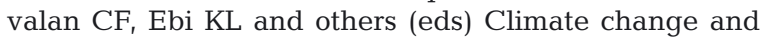


human health: risks and responses. World Health Organization, Geneva, p 61-78

Wu J, Zhou Y, Gao Y, Fu JS and others (2014) Estimation and uncertainty analysis of impacts of future heat waves on mortality in the eastern United States. Environ Health Perspect 122:10-16

Yang J, Ha J (2013) Estimation of future death burden of

Editorial responsibility: Eduardo Zorita, Geesthacht, Germany high temperatures from climate change. Korean J Environ Health Sci 39:19-31

* Zhao M, Running SW, Heinsch FA, Nemani RR (2011) MODIS-derived terrestrial primary production. In: Ramachandran B, Justice CO, Abrams MJ (eds) Land remote sensing and global environmental change. Springer, New York, NY, p 635-660

Submitted: May 30, 2016; Accepted: November 30, 2016 Proofs received from author(s): March 4, 2017 